\title{
An Experimental Method for Determination of the Refractive Index of Liquid Samples Using Michelson Interferometer
}

\author{
B. AbBas* and M. Alshikh Khalil \\ Atomic Energy Commission, P.O. Box 6091, Damascus, Syria
}

\begin{abstract}
(Received January 6, 2014; revised version May 26, 2015; in final form September 28, 2015)
A new experimental and theoretical method has been presented for measuring the refractive index of liquids and transparent solids. The experimental setup is based on a modified version of the Michelson interferometer employing a rotation stage. This technique allows us the determination of the refractive index of a given liquid (or a transparent sample) accurately to high precision, with an accuracy limited only by the precision in the determination of the rotation angle.
\end{abstract}

DOI: 10.12693/APhysPolA.129.59

PACS: 78.20.Ci, 78.40.-q, 07.60.Ly

\section{Introduction}

The refractive index is an important optical parameter in many fields such as in pharmaceuticals, food production, and other chemical-based industries to monitor purity of the end product. The refractive index data for some liquids cannot be found in reference books in many cases, and must be measured if needed. Numerous methods for measuring the refractive index of a liquid solution are well documented in textbooks. However, a cost effective method, proposed in this paper, providing high precision would be very attractive in a wide range of applications and industries. Also, it is often very important to be able to detect small differences of the refractive index between solutions [1]. There is a spectrum of techniques for determining the refractive index of liquids. For example, Grange et al. [2] and Singh et al. [3] accurately measured the refractive index of liquid solutions via measuring the minimum angle of deviation of a light beam passing through a triangular cell filled up with a liquid. This method has been found to be relatively simple for obtaining the refractive index of liquid solutions when neither high precision nor accuracy is required. However, a telescope must often be used to locate the position changes in the refracted beam. The probability of an error following determination of the angle is high. Leung and Vandiver [4] developed an automated refractometer based on laser beam displacement passing the liquid. However, two measurements must be made: with the cell full of liquid and with empty one. Other methods require measurement of the critical angle at the boundary between the liquid and the cell containing it [4-6], and then an accurate value of the refractive index of the cell walls at the laser wavelength is needed.

Recently, interferometric measurement techniques have been widely applied in determining the refractive

*corresponding author; e-mail: pscientific@aec.org.sy index of fluids. Suhadolnik [7] developed an optical fiber interferometeric refractometer, which is a combination of Mach-Zehnder and Michelson interferometers. Kachiraju and Gregory have designed two clever techniques based on a modified Michelson interferometer for measuring the refractive indices of liquids [8]. The first technique consists in analysis of a single fringe, making it very fast, although not very accurate. The second technique, requiring more time, relies on the fringe-counting method as the optical path length through the liquid is changed by a substantial amount. However, their techniques are time consuming and complicated because they require the linearly moving mirror inside the liquid cell, as well as image processing software to record, analyze, and accurately count the interference fringes and determine their FWHM. Ince et al. have presented a numerical method for determining refractive index of a glass sample from an implicit function of its optical path within the sample arm of a Michelson interferometer [9]. Rotation of the sample from normal incidence causes the light beam to suffer increasing refraction since the optical path in the air decreases, and increases in the glass sample.

In the present work, we used a modified Michelson technique, in which the liquid-containing cell is placed on motorized rotating stage, with all mirrors fixed. The number of the fringes varying during rotation of the sample within a pre-determined range of angles is counted.

\section{Experimental}

\subsection{Michelson interferometer}

The experimental setup is a modified Michelson interferometer as sketched in Fig. 1. A high power TEM $\mathrm{T}_{00}$ plane polarized Gaussian beam He-Ne laser (model 31$2140-000$, Coherent) nominally $632.8 \mathrm{~nm}$ wavelength and $5 \mathrm{~mW}$ of intensity was used as the light source. The collimated beam was split by a beam splitter into two beams that travel perpendicular to each other. The reference beam travels to a fixed mirror (M1), where it is reflected back to the beam splitter and to the detector. The other beam passing the liquid is reflected by the fixed 


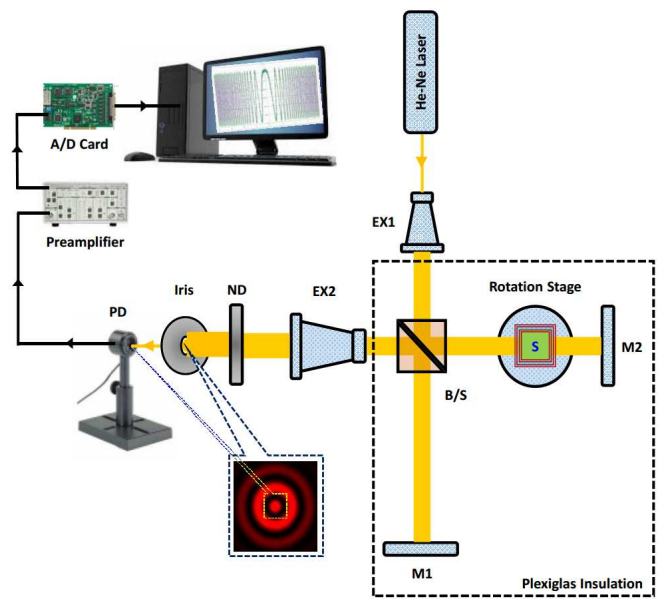

Fig. 1. Experimental setup: $\mathrm{S}$ is the liquid sample, $\mathrm{B} / \mathrm{S}$ is a 50:50 beam splitter, EX's are beam expanders, M's are the interferometer's mirrors, ND is a neutral density filter, and PD is a photodiode.

mirror (M2) back through the beam splitter to the detector. The two beams interfere at the detector and circular fringes are observed when the mirrors are aligned. A central bright fringe was observed when the optical path difference between the beams was (assumed to be) zero. Alternating central bright and dark fringes were observed by rotating the cell containing the liquid. The intensity variation of the central fringe passing through the iris and reaching the photodiode was measured and readout by a computer through a low noise current preamplifier (SR570, Stanford Research Systems), a lock-in amplifier (SR850, Stanford Research Systems), and an IEEE interfacing card (National Instruments). The rotation stage model was 8MR150-1 (Standa, Inc.), supplied with a ZSS43.200.1.2 step motor, which provides a 0.6 arcmin resolution, was connected to the PC via a $8 \mathrm{SMC} 1-\mathrm{USBh}$ controller (Standa, Inc.), which provides the possibility of driving the rotational stage by $1 / 8$ of step, which is equivalent to $0.00125^{\circ}$. An A/D card was used to control and record the experimental data along with a dedicated software program written in Borland $\mathrm{C}++$. Finally, a plot of the light intensity versus the rotation angle was generated.

\subsection{The liquid cell}

The liquid cell described in Fig. 1 was $10 \mathrm{~mm}$ rectangular shaped with an optically flat quartz window on both sides. The liquid cell was filled with the liquid for which the refractive index was being measured, and mounted on the rotation stage. The cell was aligned on the rotation stage in such a way that the clear faces of the liquid cell and the mirror were normal to the incident beam.

Additionally, the rotational stage and the interferometer mirrors were insulated by a Plexiglas box with only two apertures to allow the laser beam to enter and exit the interferometer section as illustrated in Fig. 1. The sample temperature was monitored by a thermocou- ple fixed to the sample, and connected to a heat controller (model 370, Lake Shore Cryotronics, Inc.). It was found that the fluctuation of the temperature inside the Plexiglas box in a closed laboratory was about $0.05^{\circ} \mathrm{C}$ during the measurement which typically took a few minutes. Moreover, the experimental setup was placed on a vibration-isolated table.

\subsection{Calibration procedure}

The calibration procedure started by manually setting the sample on the rotation stage so that the laser light was incident on the sample face at normal angle. Then, the rotation stage was rotated to the desired starting angle automatically via the driving programme that we wrote. After that, the experimental procedure took place for recording the variation of the light intensity as a function of the rotating angle. As such, it was found that the automatic moving of the sample to the starting angle may be varied from one trial to another by an angle of $\pm 0.0005^{\circ}$ or less. This small error was seen when drawing the experimental result using Excel or Origin packages, whereby a small shift in the central fringe was observed. This shift manifested the error in setting the starting angle of our experimental procedure, and was taken into account as the experimental error of $\phi$.

\section{Modeling}

The mathematicl derivation and desciption of the lightcell geometry is shown in Fig. 2. If the cuvette is absent, the light will trace the $\overline{P V}$ path. Placing the cuvette in the path of the light will force the light to change its course following the refraction law. The optical path dif-

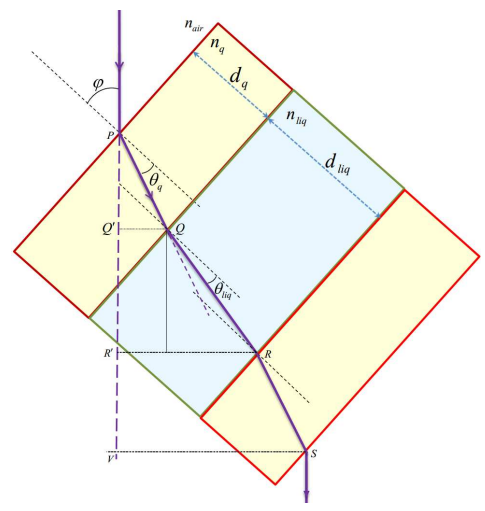

Fig. 2. The geometry of the experiment: symbols are explained in the text.

ference $(\Delta)$ between these two paths is given by

$$
\Delta=2 n_{\mathrm{q}} \overline{P Q}+n_{\text {liq }} \overline{Q R}-n_{\text {air }} \overline{P V}
$$

where

$$
\begin{aligned}
& \overline{Q R}=\frac{d_{\text {liq }}}{\cos \theta_{\text {liq }}}, \quad \overline{P Q}=\frac{d_{\mathrm{q}}}{\cos \theta_{\mathrm{q}}}, \\
& \overline{Q^{\prime} R^{\prime}}=\frac{d_{\text {liq }}}{\cos \theta_{\text {liq }}} \cos \left(\varphi-\theta_{\text {liq }}\right), \\
& \overline{P Q^{\prime}}=\overline{R^{\prime} V}=d_{\mathrm{q}} \frac{\cos \left(\varphi-\theta_{\mathrm{q}}\right)}{\cos \theta_{\mathrm{q}}} .
\end{aligned}
$$


Substituting these relations in Eq. (1) and rearranging the resulting terms, the optical path difference will be expressed as

$$
\begin{aligned}
& \Delta_{\varphi}=\frac{2 n_{\mathrm{q}} d_{\mathrm{q}}}{\cos \theta_{\mathrm{q}}}+\frac{n_{\text {liq }} d_{\text {liq }}}{\cos \theta_{\text {liq }}}-2 d_{\mathrm{q}} n_{\text {air }} \frac{\cos \left(\varphi-\theta_{\mathrm{q}}\right)}{\cos \theta_{\mathrm{q}}} \\
& -\frac{d_{\text {liq }}}{\cos \theta_{\text {liq }}} n_{\text {air }} \cos \left(\varphi-\theta_{\text {liq }}\right)
\end{aligned}
$$

$$
\begin{aligned}
& \Delta_{\varphi}=4 d_{\mathrm{q}}\left[\sqrt{n_{\mathrm{q}}^{2}-n_{\mathrm{air}}^{2} \sin ^{2} \varphi}-n_{\text {air }} \cos \varphi\right] \\
& +2 d_{\text {liq }}\left[\sqrt{n_{\text {liq }}^{2}-n_{\text {air }}^{2} \sin ^{2} \varphi}-n_{\text {air }} \cos \varphi\right],
\end{aligned}
$$

where $n_{\mathrm{q}}$ is the refractive index of the quartz wall for the wavelength of the source light, $d_{\mathrm{q}}$ is the thickness of the quartz wall, $d_{\text {liq }}$ is the thickness of the liquid, $n_{\text {air }}$ is the refractive index of air, and $\varphi$ is the rotation angle. If the light beam is incident at normal angle on the quartz face: $\varphi=\theta_{\mathrm{q}}=\theta_{\text {liq }}=0$, so that the optical path difference is reduced to

$$
\begin{aligned}
& \Delta_{\text {normal }}=2 \times\left(2 n_{\mathrm{q}} d_{\mathrm{q}}+n_{\text {liq }} d_{\text {liq }}\right. \\
& \left.-2 d_{\mathrm{q}} n_{\text {air }}-d_{\text {liq }} n_{\text {air }}\right) .
\end{aligned}
$$

Upon turning the cell from the initial normal position through an angle $\varphi$, the change in the path difference between the two beams is $\left(\Delta_{\varphi}-\Delta_{\text {normal }}\right)$, which corresponds to $m$ fringes appearing or disappearing at the center of the fringe pattern. In this case,

$$
\begin{gathered}
2 k_{0}\left(\Delta_{\varphi}-\Delta_{\text {normal }}\right)=2 \pi m \Rightarrow \\
m=\frac{2}{\lambda}\left(\Delta_{\varphi}-\Delta_{\text {normal }}\right) .
\end{gathered}
$$

This equation can be rearranged, so that a general equation for the relationship between the number of fringes, $m$, appearing or disappearing at the center of the fringe pattern, and the rotation angle will be

$$
\begin{aligned}
m & =\frac{2}{\lambda}\left[2 d_{\mathrm{q}}\left(\sqrt{n_{\mathrm{q}}^{2}-n_{\text {air }}^{2} \sin ^{2} \varphi}-n_{\text {air }} \cos \varphi\right)\right. \\
& +d_{\text {liq }}\left(\sqrt{n_{\text {liq }}^{2}-n_{\text {air }}^{2} \sin ^{2} \varphi}-n_{\text {air }} \cos \varphi\right) \\
& \left.-\left(2 n_{\mathrm{q}} d_{\mathrm{q}}+n_{\text {liq }} d_{\text {liq }}-2 d_{\mathrm{q}} n_{\text {air }}-d_{\text {liq }} n_{\text {air }}\right)\right] .
\end{aligned}
$$

This equation is valid in both cases where the refractive index of the liquid is greater than or smaller than the refractive index of the cuvette.

In the case of an empty cuvette, the refractive index of air can be measured using Eq. (6) and replacing $n_{\text {liq }}=n_{\text {air }}$, which becomes

$$
\begin{aligned}
m^{\prime} & =\frac{2}{\lambda}\left[2 d_{\mathrm{q}}\left(\sqrt{n_{\mathrm{q}}^{2}-n_{\text {air }}^{2} \sin ^{2} \varphi}-n_{\text {air }} \cos \varphi\right)\right. \\
& \left.-\left(2 n_{\mathrm{q}} d_{\mathrm{q}}-2 d_{\mathrm{q}} n_{\text {air }}\right)\right] .
\end{aligned}
$$

On the other hand, substituting Eq. (7) into Eq. (6) gives

$$
\begin{aligned}
& m=m^{\prime}+\frac{2 d_{\text {liq }}}{\lambda}\left(\sqrt{n_{\text {liq }}^{2}-n_{\text {air }}^{2} \sin ^{2} \varphi}\right. \\
& \left.-n_{\text {air }} \cos \varphi-n_{\text {liq }}+n_{\text {air }}\right),
\end{aligned}
$$

where $m^{\prime}$ is the number of fringes counted when the cuvette is empty, and $m$ is the number of fringes counted when the cuvette is filled with the liquid, in the same range of rotating angles. This equation can be used to measure the refractive index of liquids without the need of knowledge of the refractive index of the cuvette.

This method can also be used for measuring the refractive index of a slab of crystals and glass plates, reducing Eq. (6) to

$$
\begin{aligned}
m & =\frac{2}{\lambda}\left[d_{\mathrm{q}}\left(\sqrt{n_{\mathrm{q}}^{2}-n_{\text {air }}^{2} \sin ^{2} \varphi}-n_{\text {air }} \cos \varphi\right)\right. \\
& \left.-\left(n_{\mathrm{q}} d_{\mathrm{q}}-d_{\mathrm{q}} n_{\text {air }}\right)\right]
\end{aligned}
$$

where $n_{\mathrm{q}}$ is the refractive index of the glass (or crystal), $d_{\mathrm{q}}$ is its thickness.

Additionally, a nonlinear least square fit procedure was carried out, depending on the resultant light intensity of the interference,

$$
I=I_{1}+I_{2}+2 \sqrt{I_{1} I_{2}} \cos \left(k\left(\Delta_{\varphi}-\Delta_{\text {normal }}\right)\right),
$$

where $I_{1}$ and $I_{2}$ are the intensities of the beams following the two paths. The fitting procedure was executed by varying $I_{1}, I_{2}$, and $n_{\text {liq }}$ parameters. This procedure was proven very useful in order to obtain the most accurate value of the refractive index with a very small deviation.

\section{Uncertainty analysis}

Uncertainties in the refractive index measurement arise from systematic errors in angle measurements, and random errors caused by vibration, air disturbances, and laser fluctuations. Random errors are accounted for using statistical averaging techniques during the data acquisition. Systematic errors are determined from the following error analysis. Referring to Fig. 2 and Eq. (6), uncertainties in $\phi, n_{\mathrm{q}}, n_{\text {air }}, d_{\mathrm{q}}$, and $d_{\text {liq }}$ contribute to uncertainty in $n_{\text {liq. }}$. Errors arising from $d_{\mathrm{q}}, n_{\mathrm{q}}, d_{\text {liq }}$, and $n_{\text {air }}$ are considered negligible. The error of $\phi$ is taken as half of the measurement setup resolution, $\pm 0.0005^{\circ}$. Error in $n_{\text {liq }}$ increases with higher values of the refractive index of the liquids under investigation (varied between \pm 0.0001 and \pm 0.003$)$. These errors can be minimized with smaller steps (intervals) in the recorded data points as the rotation stage is rotated to the targeted angle. This procedure helps improving the accuracy of $\phi$. However, the accuracy of $\phi$ was still a main factor determining precision of the refractive index determination.

\section{Results}

\subsection{Refractive index of water}

Distilled water was chosen to validate the measurement technique discussed above. Mirrors M1 and M2 were adjusted precisely to obtain good superposition of transmitted and reflected waves. Circular interference fringes 
of high visibility were then observed on the field of view. The interference intensities were simultaneously recorded continuously. The total number of central order fringe cycles in the chosen rotation angle range was counted by recording the experimental data in a spread sheet and counting the number of peaks. The fringe count data was then used in Eq. (8) to calculate the refractive index of the water sample. The measured refractive index of the water, $n_{\text {water }}$, was 1.3316 . Figure 3 represents the measured fringes (circle points) and the corresponding nonlinear least square best fit (solid line) according to Eq. (10).

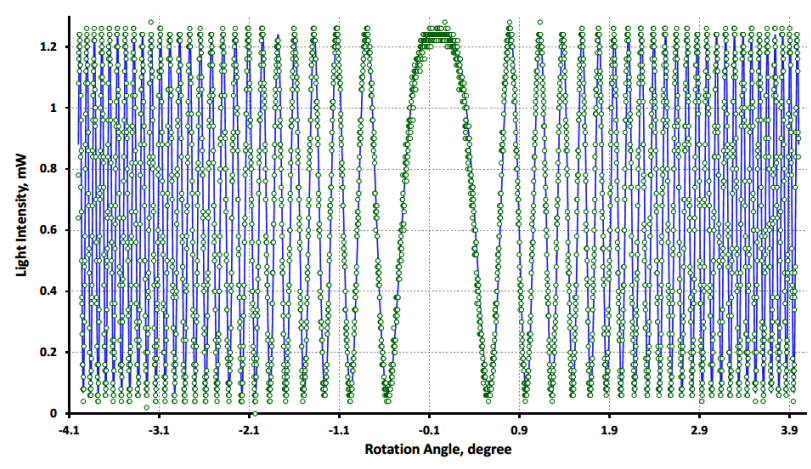

Fig. 3. The measured fringes (circle points) and the corresponding nonlinear least square fit (solid line) for water.

TABLE I

The refractive indexes of different liquid and solid samples at $632.8 \mathrm{~nm}$ laser light.

\begin{tabular}{|c|c|c|}
\hline \multirow[t]{2}{*}{ Material } & \multicolumn{2}{|c|}{ refractive index } \\
\hline & this work & others \\
\hline $\begin{array}{c}\text { air } \\
{\left[22^{\circ} \mathrm{C}\right]}\end{array}$ & $\begin{array}{c}1.00028 \\
\pm 0.00005\end{array}$ & $\begin{array}{c}1.000267^{a} \\
\pm 0.000007\left[21^{\circ} \mathrm{C}\right]\end{array}$ \\
\hline \multicolumn{3}{|c|}{ liquid samples } \\
\hline $\begin{array}{c}\text { distilled } \\
\text { water }\left[22^{\circ} \mathrm{C}\right]\end{array}$ & $\begin{array}{c}1.3316 \\
\pm 0.0001\end{array}$ & $\begin{array}{c}1.33171^{b} \\
\pm 0.00002\left[21^{\circ} \mathrm{C}\right]\end{array}$ \\
\hline $\begin{array}{c}\text { benzene } \\
{\left[22^{\circ} \mathrm{C}\right]}\end{array}$ & $\begin{array}{l}1.4951 \\
0.0002\end{array}$ & $\begin{array}{c}1.497108^{b} \\
\pm 0.00002\left[21^{\circ} \mathrm{C}\right]\end{array}$ \\
\hline $\begin{array}{l}\text { ethanol } \\
{\left[20^{\circ} \mathrm{C}\right]}\end{array}$ & $\begin{array}{c}1.3562 \\
\pm 0.0002\end{array}$ & $\begin{array}{c}1.356039^{c} \\
\pm 0.000005\left[20^{\circ} \mathrm{C}\right]\end{array}$ \\
\hline $\begin{array}{c}\text { dichloromethane } \\
(\mathrm{DCM})\left[20^{\circ} \mathrm{C}\right]\end{array}$ & $\begin{array}{c}1.4195 \\
\pm 0.0002\end{array}$ & $\begin{array}{l}- \\
-\end{array}$ \\
\hline $\begin{array}{l}\text { acetone } \\
{\left[20^{\circ} \mathrm{C}\right]}\end{array}$ & $\begin{array}{c}1.3585 \\
\pm 0.0002\end{array}$ & $\begin{array}{c}1.35782^{c} \\
\pm 0.000005\left[20^{\circ} \mathrm{C}\right]\end{array}$ \\
\hline $\begin{array}{c}\text { tetrahydrofurane } \\
\text { (THF) }\left[20^{\circ} \mathrm{C}\right]\end{array}$ & $\begin{array}{c}1.4034 \\
\pm 0.0002\end{array}$ & $\begin{array}{l}- \\
-\end{array}$ \\
\hline \multicolumn{3}{|c|}{ solid slabs } \\
\hline $\begin{array}{l}\text { quartz } \\
{\left[22^{\circ} \mathrm{C}\right]}\end{array}$ & $\begin{array}{c}1.4571 \\
\pm 0.0001\end{array}$ & $\begin{array}{c}1.457012^{d} \\
\pm 0.000001\left[20^{\circ} \mathrm{C}\right]\end{array}$ \\
\hline $\begin{array}{l}\text { sapphire } \\
{\left[22^{\circ} \mathrm{C}\right]}\end{array}$ & $\begin{array}{c}1.7653 \\
\pm 0.0003\end{array}$ & $\begin{array}{c}1.765894^{e} \\
\pm 0.000001\left[20^{\circ} \mathrm{C}\right]\end{array}$ \\
\hline
\end{tabular}

\subsection{The refractive index of other materials}

The refractive indices of different liquid samples and solid transparent substrates were also measured. The results are shown in Table I, along with a comparison with those published data in the literature for some substance samples we have used. It is noteworthy to say that the noticed differences in the refractive index of any material used by the researchers may be attributed to the pollution, concentration, or impurity of this material, as well as the experimental conditions under which the measurements were carried out. Therefore, one cannot expect to get identical results or values for the refractive index, which was what we have noticed many times. As an example: our material (benzene) was purchased from Fluka, with a purity of $>99 \%$ and a density of $0.878 \mathrm{~g} / \mathrm{mL}$ at $20^{\circ} \mathrm{C}$, but there are different concentrations in the market such as that sold by Sigma-Aldrich with purity of $99.8 \%$ and a density of $0.874 \mathrm{~g} / \mathrm{mL}$ at $25^{\circ} \mathrm{C}$. Another factor which may be taken into account for the differences in the numbers found in literature is the refractive index of the material at the sodium line. For example, our benzene has $n_{\mathrm{D}}^{20}=1.500$ whereas that sold by Sigma-Aldrich has the value of $n_{\mathrm{D}}^{20}=1.501$. However, in the light of the agreement of our results with those found in literature, we argue that the measured value of the refractive index of the used benzene is acceptable.

\section{Conclusion}

In the present paper, we have derived the relationship between the refractive index of liquid solutions and the number of central fringes appearing or disappearing as the liquid samples are rotated within a certain range of angles. We have successfully demonstrated and determined the refractive index of a wide range of solutions, as well as transparent solid slabs of crystals and glasses.

On a different note, it is needless to say that this method is quite capable of measuring the thickness of the sample under test if its refractive index is known.

\section{Acknowledgments}

The authors would like to express their thanks to Prof. I. Othman for his continuous encouragement, guidance and support.

\section{References}

[1] H.B. Thomas, K. Matsumoto, T. Eiju, K. Matsuda, N. Ooyama, Appl. Opt. 30, 745 (1991).

[2] B.W. Grange, W.H. Stevenson, R. Viskanta, Appl. Opt. 15, 858 (1976).

[3] V.K. Singh, B.B.S. Jaswal, V. Kumar, R. Prakash, P. Raib, J. Integr. Sci. Technol. 1, 13 (2013).

[4] A.F. Leung, J.J. Vandiver, Opt. Eng. 42, 1128 (2003).

[5] E. Moreels, C. deGreef, R. Finsy, Appl. Opt. 23, 3010 (1984).

[6] M.V.R.K. Murty, R.P. Shukla, Opt. Eng. 18, 177 (1979). 
[7] A. Suhadolnik, Meas. Sci. Technol. 18, 1205 (2007).

[8] S.R. Kachiraju, D.A. Gregory, Opt. Laser Technol. 44, 2361 (2012).

[9] R. Ince, E. Sınır, M. Feeney, M.H. Yükselici, A.T. Ince, Opt. Commun. 3831, 281 (2008).

[10] A.A. Zaidi, Y. Makdisi, K.S. Bhatia, I. Abutahun, Rev. Sci. Instrum. 60, 803 (1989).
[11] J.M. St-Arnaud, J. Ge, J. Orbriot, T.K. Bos, Ph. Marteau, Rev. Sci. Instrum. 62, 1114 (1991).

[12] I.H. Malitson, J. Opt. Soc. Am. 55, 1205 (1965).

[13] W.J. Tropf, M.E. Thomas, E.W. Rogala, in: Handbook of Optics: Optical Properties of Materials, Nonlinear Optics, Quantum Optics, Ed. M. Bass, Vol. IV, 3rd ed., McGraw-Hill, New York 2010, p. 2.60. 